
\title{
25 Research Suare \\ Study on the Dynamic Characteristics of Subway Tunnel Billboard Under Wind and Vibration Loads
}

\author{
Yong-hang Sun \\ Northeastern University \\ Zhong Luo ( $\boldsymbol{\nabla}$ zhluo@mail.neu.edu.cn ) \\ Northeastern University \\ Yu Wang \\ Northeastern University \\ Kai Wei \\ Northeastern University \\ Gui-xin Han \\ Northeastern University
}

Original Article

Keywords: Vibration load, Wind load, Dynamic characteristics, Subway tunnel, billboards

Posted Date: June 24th, 2020

DOl: https://doi.org/10.21203/rs.3.rs-37337/v1

License: (c) (1) This work is licensed under a Creative Commons Attribution 4.0 International License.

Read Full License 


\section{Title page}

\section{Study on the dynamic characteristics of subway tunnel billboard under wind and vibration loads}

Yong-hang Sun, born in 1996, is currently a master candidate at School of Mechanical Engineering \& Automation, Northeastern University, China.

E-mail: sunyonghang1014@gmail.com

Zhong Luo, born in 1978, is currently a professor at Northeastern University, China. He received his PhD degree from Northeastern University, China, in 2007. His research interests include mechanical dynamics and control, model test theory and method.

Tel: +86-2483680540; E-mail: zhluo@mail.neu.edu.cn

Yu Wang, born in 1997, is currently a master candidate at School of Mechanical Engineering \& Automation, Northeastern University, China.

E-mail: 1784586734@qq.com

Kai Wei, born in 1997, is currently a master candidate at School of Mechanical Engineering \& Automation, Northeastern University, China.

E-mail: 1095423999@qq.com

Gui-xin Han, born in 1995, is currently a master candidate at School of Mechanical Engineering \& Automation, Northeastern University, China.

E-mail: 1027904372@qq.com

\section{Corresponding author: Zhong Luo E-mail: zhluo@mail.neu.edu.cn}




\title{
Study on the dynamic characteristics of subway tunnel billboard under wind and vibration loads
}

\author{
Yong-hang Sun $^{1} \cdot$ Zhong Luo $^{1,2,3} \cdot$ Yu Wang $^{1} \cdot$ Kai Wei $^{1} \cdot$ Gui-xin Han $^{1}$
}

Received June xx, 201x; revised February xx, 201x; accepted March xx, 201x

(c) Chinese Mechanical Engineering Society and Springer-Verlag Berlin Heidelberg 2017

\begin{abstract}
In order to avoid the damage of billboards in the subway tunnel, the dynamic characteristic of them subjected to the wind load, the train-induced vibration load and both of them (multi-load) were analyzed. First, computational fluid dynamics (CFD) was used to simulate unsteady airflow when a train runs in tunnel. Second, the train-induced vibration load is obtained by the fitting formula. Finally, a finite element model of Shenyang Metro was built and the response of the billboard under different loads were obtained. The result shows that the structural response of the billboard under multi-load is severer than each single load. For the wind load, it has a greater influence on the equivalent stress of the billboard, while for the vibration load, it has a greater influence on the acceleration of the billboard. The response under multiple loads includes the characteristics of two loads acting separately. This study reveals the dynamic characteristic of billboards under different loads, which will help to improve the stability and safety life of them.
\end{abstract}

Keywords: Vibration load $•$ Wind load $•$ Dynamic characteristics

- Subway tunnel $\bullet$ billboards

\section{Introduction}

Most of cities of China are developing or planning the subway projects to alleviating effect on traffic congestion, so the safety of the subway has drawn public attention in

\section{Zhong Luo}

zhluo@mail.neu.edu.cn

1 School of Mechanical Engineering \& Automation, Northeastern University, Shenyang 110819, PR China

2 China Key Laboratory of Vibration and Control of Aero-Propulsion System Ministry of Education, Northeastern University, Shenyang 110819, PR China

3 State Key Laboratory of Structural Analysis for Industrial Equipment, Dalian University of Technology, Dalian 116024, PR China recent years. During the operation of the train, the air in the tunnel is squeezed, and the compressed air form the piston wind. When the train pass, the piston wind pressure acts on billboards and other facilities in the tunnel. At the same time, the dynamic interaction between the train wheels and rails also results in vibration loads on the facilities and equipment in the tunnel [1]. So billboards and other facilities in the subway tunnel are subjected to the wind load, the vibration load and the noise load, etc. These loads could lead to the shedding and destruction of billboards, which will pose serious threat to the operational safety of the subway [2]. The billboards in tunnel is shown in Figure 1 .

Previous studies on piston wind mainly focused on the wind characteristics in the tunnel. J. Y. Kim and K. Y. Kim [3] performed experiments in a scale model tunnel to investigate the variations in air pressure and velocity cause by the train-induced flow. Han et al. [4] established a model of the actual tunnel, and analyzed the variant characteristics of air pressure on billboards in the tunnel. Camelli et al. [5] used a real-scale model of a subway station with multiple exits to the outside to simulate the airflow across two station levels with four trains arriving and leaving. Yang et al. [6] simulated train-induced airflow patterns inside a subway station and presented a set of simplified methods for determining airflow rates.

The dynamic response of the shield tunnels under the train-induced vibration has also attracted considerable attentions. Forrest et al. [7] built an analytical 3D model for a circular cross-section railway tunnel and a model wave equation for an elastic continuum to calculate the ground vibration. Yuan et al. [8] Studied dynamic response of the rail structure and tunnel under moving harmonic load, the effects of load velocity on track response and 
displacement were investigated. Gardien et al. [9] put the wave propagation through the soil is computed separately from the dynamic load of the train on the viaduct present a modular model to predict the railway induced vibration level. Hung et al. [10] used finite/infinite element approach for simulate the soil-tunnel interaction system with semi-infinite domain, and accurate predict the resonance peak and frequency of the ground vibrations caused by the subway load. Yan et al. [11, 12] used the fitting formula for train load to analyze the envelope curves of the major principal stress and the acceleration time-history range at the intersection locations at different surrounding rock grades and train speeds. Xue [13] developed a three-dimensional nonlinear numerical rail-tunnel model and revealed that the spatial dynamic response displacement, acceleration and stresses in different position is simultaneously. Real et al. [14] established a 3D and a 2D numerical finite element model of a railway tunnel to predict train-induced vibrations, and contrast the difference between the two models.

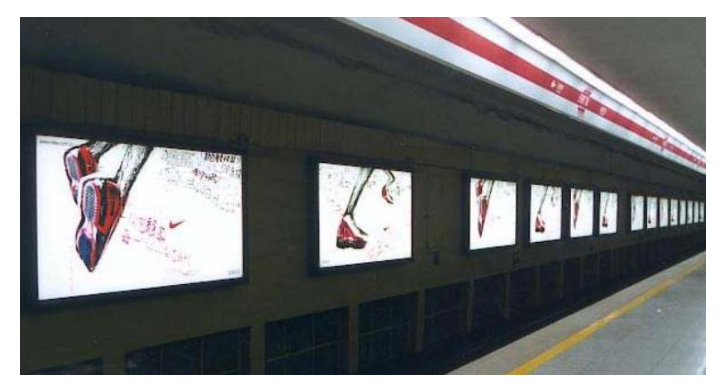

Figure 1 The billboards in tunnel

It is can be seen that most of the current literature pays attentions to the piston wind characteristics and the dynamic response and of the tunnel, while there is a lack of research on the dynamic characteristic of the tunnel affiliated facilities like billboards. Under the long-term function of the wind load and the train-induced vibration load, these structures are prone to shed and damage, which will cause a serious influence on the safety operation of the metro. Therefore, it is of great significant to study the dynamic characteristics of the billboard under the wind load and the vibration load, which could be helpful to maintain and reinforcement design of the facilities in the subway tunnel.

The study is focus on the dynamic characteristic of the billboard in the subway tunnel, and the structural response difference between the different types of load. First, the wind load for the billboard is obtained by the CFD analysis in FLUENT software [15]. After that, the train-induced vibration load is obtained by the fitting formula. Finally, the structural response of the billboard under different types of load is analyzed in ABAQUS software [16]. A flowchart of the study is shown in Figure 2.

\section{The governing equations}

\subsection{Governing equations of fluid flow}

For simulations, air was considered incompressible and airflow in a subway tunnel was defined as high-Reynolds number turbulent flow. Thus, equations of conservation of mass and momentum for unsteady flow can be written as follows [17]:

$$
\frac{\partial \rho}{\partial_{t}}+\frac{\partial}{\partial_{x_{i}}} \rho_{u_{i}}=0
$$

where $\rho$ is density of the fluid, $t$ is time, $x_{i}$ is the position coordinate, and $u_{i}$ is the fluid velocity.

$$
\frac{\partial \rho_{u_{i}}}{\partial_{t}}+\frac{\partial \rho_{u_{i} u_{j}}}{\partial_{x_{j}}}=-\frac{\partial p}{\partial_{x_{i}}}+\frac{\partial}{\partial_{x_{j}}}\left(\mu \frac{\partial u_{i}}{\partial_{x_{j}}}-\overline{\rho_{u_{i}^{\prime} u_{j}^{\prime}}^{\prime}}\right)
$$

where $-\overline{\rho_{u_{i}^{\prime} u_{j}^{\prime}}}$ is the turbulent Reynolds stress and subscript $i, j=1,2,3$. To be able to solve the governing equations, a turbulence model must be selected.

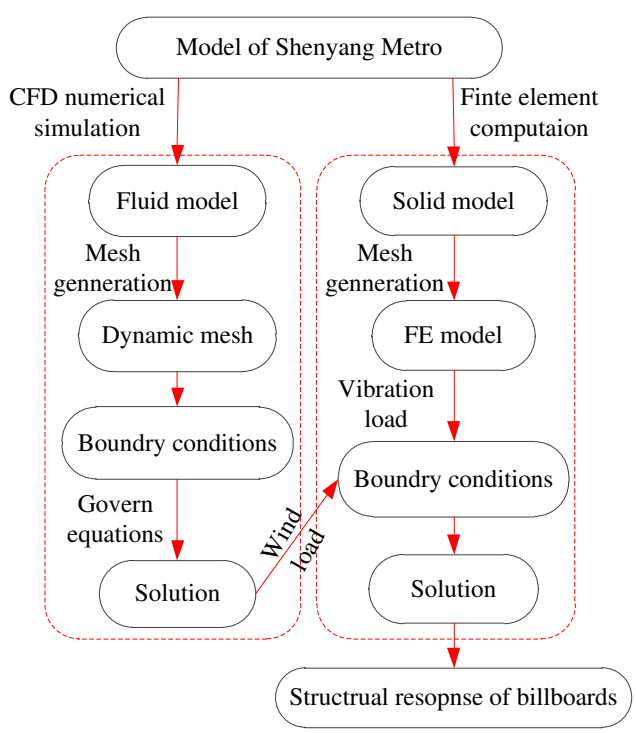

Figure 2 Flowchart of the study

\subsection{Structural kinetic equation}

Dynamic response of the structure is generally expressed as

$$
M \mathbb{Z}^{+} C \mathrm{x}^{+} K x={ }_{F} t
$$


where $M$ is the matrix of mass, $C$ is the matrix of damping related to the structural material, and $K$ is the matrix of stiffness. \& and $x$ are the acceleration vector, velocity vector and displacement vector of the system, respectively. $F(t)$ refers to nodal force vector changing along with time.

The explicit dynamics analysis procedure will depend on implementing the explicit integration scheme together with the use of diagonal element mass matrix M. Eq.(4) is evaluated using the explicit central-diff erence integration rule:

$$
\left\{\begin{array}{c}
x^{n^{+1}}=x^{n}+\Delta_{t u^{n+1 / 2}} \\
u^{n^{+}+1 / 2}=u^{n^{-1 / 2}}+\Delta_{t} \cdot M^{-1} \cdot F_{\text {int }}+F_{\text {ext }}
\end{array}\right.
$$

where $F_{\mathrm{int}}, F_{\text {ext }}$ represent the internal and external force vectors, respectively. By solving the Equation (4), dynamic response under the multi-load can be achieved.

\section{Determination of the wind load}

\subsection{Establishment of the model}

The FLUENT commercial code is used to simulate the three-dimensional unsteady flow field in the tunnel. A cross-section of a typical tunnel of the Shenyang Metro is illustrated in Figure 3. The tunnel is $1200 \mathrm{~m}$ in length, and the train line and the center line offset by $200 \mathrm{~mm}$. The specific parameter of the train and billboard are shown in Table 1. The train is set at $183 \mathrm{~m}$ from the tunnel entrance and its running status is acceleration-uniform speed-deceleration. The time of train operation is $72 \mathrm{~s}$. The specific simulation parameter settings are the same as those in Ref. [4]. The Model of the tunnel is shown in Figure 4.

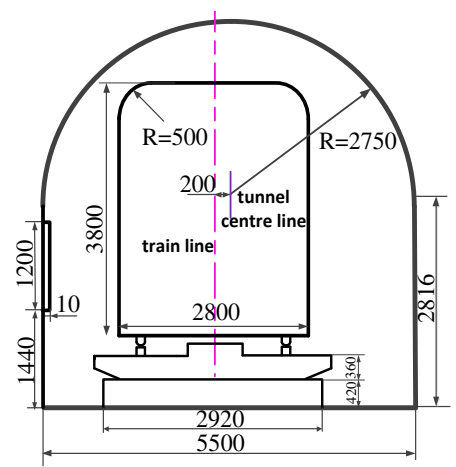

Figure 3 Cross section view of tunnel (mm)

\subsection{Code validation}

A simulation model of Ref. [3] was established to verify the method. It is a 1:20-scale of a subway tunnel that is 210 $\mathrm{mm}$ wide, $250 \mathrm{~mm}$ tall, and $39 \mathrm{~m}$ long. Four pressure transducers were installed along the longitudinal direction of the tunnel at $8.5 \mathrm{~m}, 15 \mathrm{~m}, 23.5 \mathrm{~m}$, and $30.5 \mathrm{~m}$. A schematic diagram of the experimental layout is presented in Figure 5.

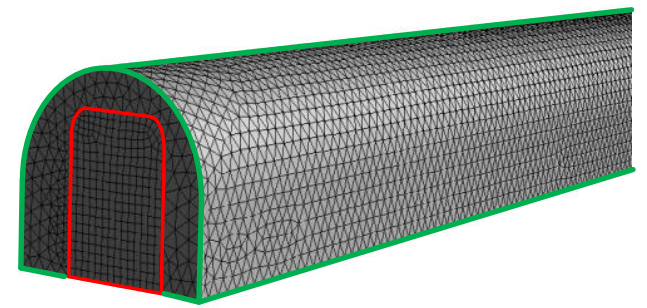

Figure 4 Model of the tunnel

Table 1 Tunnel and train parameter

\begin{tabular}{cccc}
\hline Parameters & Values & Parameters & Values \\
\hline Train speed & $60 \mathrm{~km} / \mathrm{h}$ & Billboard length & $3.6 \mathrm{~m}$ \\
Train length & $118.26 \mathrm{~m}$ & Billboard width & $0.1 \mathrm{~m}$ \\
Train height & $3.8 \mathrm{~m}$ & Billboard height & $1.2 \mathrm{~m}$ \\
Train width & $2.8 \mathrm{~m}$ & Train acceleration & $1 \mathrm{~m} / \mathrm{s}^{2}$ \\
\hline
\end{tabular}

Figure 6 shows the comparison of pressure coefficient $\mathrm{Cp}$ between the simulation and the experiment. The simulation value in this paper is basically consistent with the experimental value. The relative errors obtained in this study of the PT1, PT2, and PT3 are 6.8\%, 7.6\% and 7.4\%, respectively. The code of the paper is able to predict the wind load for the billboard with a sufficient degree of accuracy.

\subsection{Result and analysis}

Figure 7 shows the pressure on the surface of the billboard at the train speed of $60 \mathrm{~km} / \mathrm{h}$. When the train starts, the pressure quickly reaches a peak with the increase of train speed. When the train speed reaches the maximum and keeps a uniform speed, the air flow gradually stabilize and the pressure decreased slightly. Under the effect of piston wind, the pressure drops suddenly during the train passing by the billboard. When the train arrived at the billboard, the billboard retains a negative pressure; after the train leaving for a period of time, the pressure begins to rise gradually and relief to a positive value. Finally, because of the departure of the train, the pressure on the surface of the billboard decreases to zero.

\section{Establishment of the finite element model}

\subsection{The model description}

The model is established according to the characteristic of the subway tunnel structure. Figure 8 shows the finite element model. The cross-section size parameter of the model is $120 \mathrm{~m} \times 70 \mathrm{~m}$. Meanwhile, the tunnel model length is set as $300 \mathrm{~m}$ to simulate that the train approaches and 
leaves the billboard. The actual soil environment is simplified, and considered to be formed by three horizontal layers which are regarded as elastic-plastic material, called
Soil layer 1, 2, and 3. The tunnel is located at the depth of $22 \mathrm{~m}$ in the Soil layer 2.

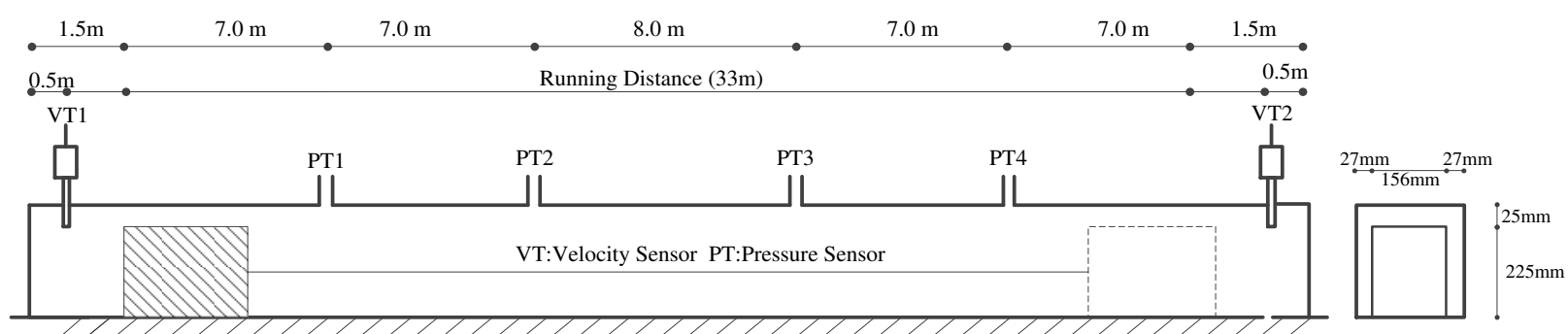

Figure 5 Schematic diagram of the experimental layout [3].

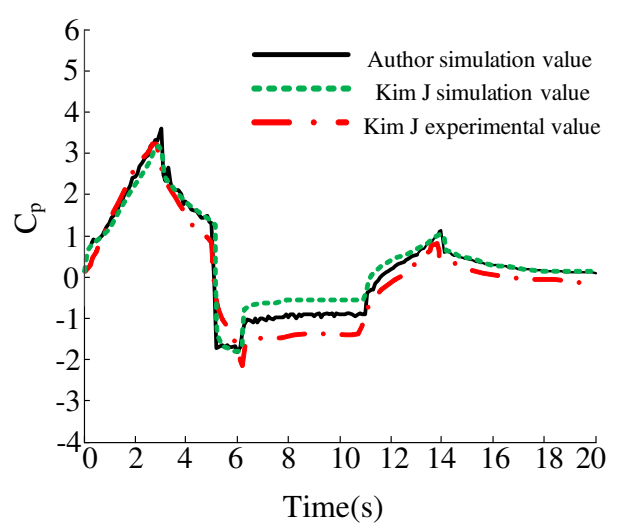

a

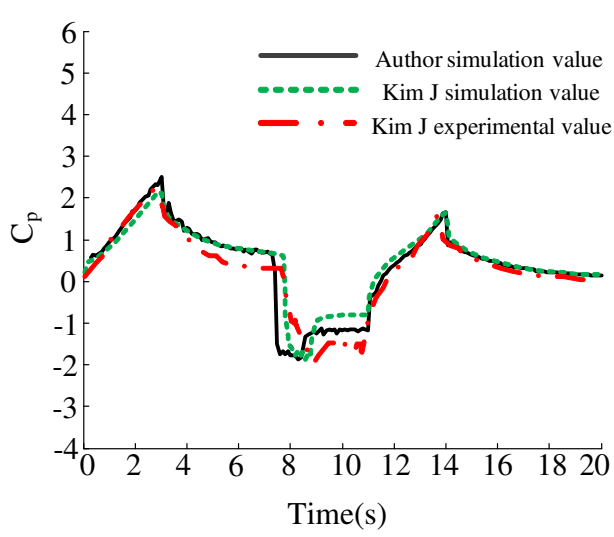

c

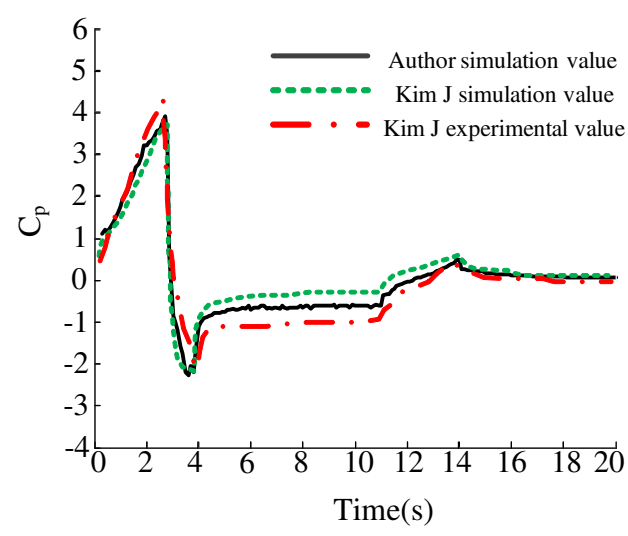

b

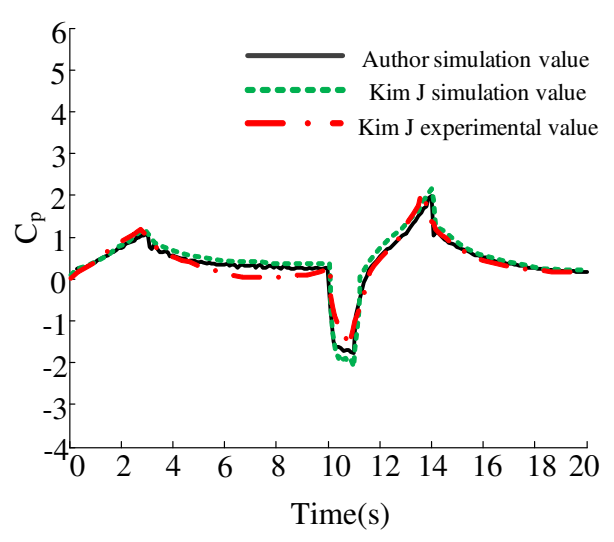

d

Figure 6 Comparisons of pressure coefficient Cp on monitoring points: (a) PT1; (b) PT2; (c) PT3; (d) PT4

The material of lining is C30 concrete, and the Mohr-Coulomb (M-C) constitutive relationship is used in the calculation. According to the investigation of Shenyang subway tunnel, the soil and material properties are summarized in Table 2 and 3.

In actual situations, vehicles and tracks have the characteristics of complex structure and coupling. In this model, the vehicle and the rail model is simplified for specific research contents [18]. The vehicle and the rail model is shown in Figure 9. Considering the structural characteristics of the actual subway tunnel, the model is divided into several parts: the rail, the floating slab track, the backfill layer and the tunnel lining. According to the actual wheel-rail contact characteristic, the wheel and the rail surface are set as contact pair. And the wheel-rail normal force is determined by the Hertz contact theory. 
And the vehicle and the rail model parameters are shown in Table 4.

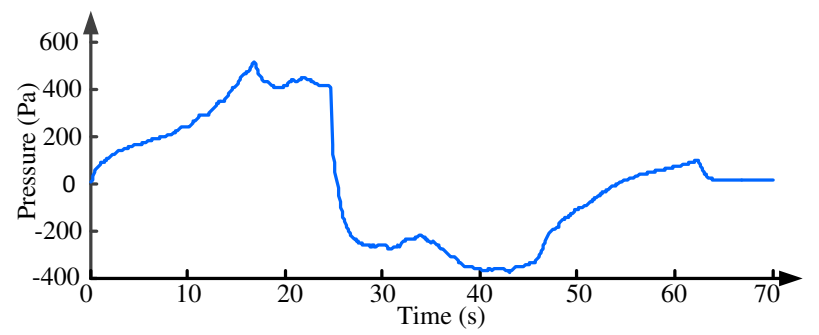

Figure 7 Pressure curve on the surface of the billboard at the train speed of $60 \mathrm{~km} / \mathrm{h}$

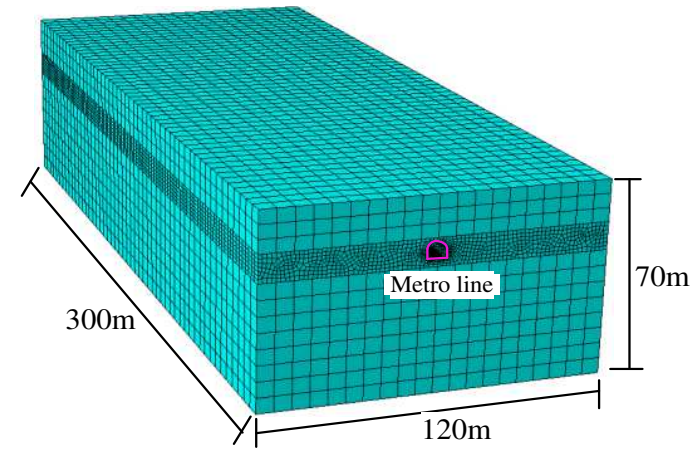

Figure 8 Finite element model of the tunnel

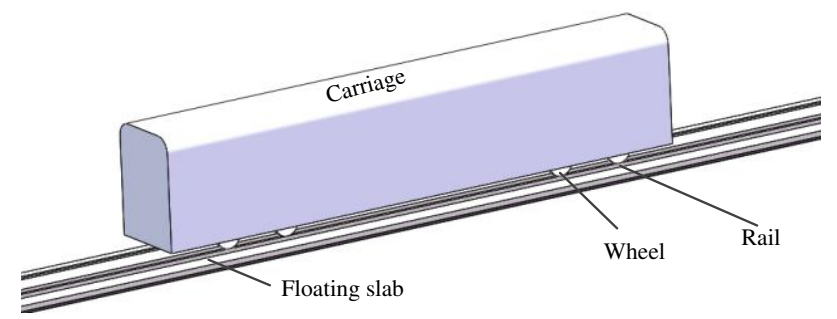

Figure 9 The vehicle and the rail model

Table 2 Soil layer parameters

\begin{tabular}{cccccc}
\hline Position & $\begin{array}{c}\text { Depth } \\
(\mathrm{m})\end{array}$ & $\begin{array}{c}\text { Density } \\
\left(\mathrm{kg} / \mathrm{m}^{3}\right)\end{array}$ & $\begin{array}{c}\text { Elasticity } \\
\text { modulus(MPa) }\end{array}$ & $\begin{array}{c}\text { Poisson } \\
\text { ration }\end{array}$ & $\begin{array}{c}\text { Friction } \\
\text { angle }\left({ }^{\circ}\right)\end{array}$ \\
\hline $\begin{array}{c}\text { Soil } \\
\text { layer 1 } \\
\text { Soil }\end{array}$ & $0 \sim 15$ & 1887.76 & 11.25 & 0.32 & 22 \\
$\begin{array}{c}\text { layer 2 } \\
\text { Soil } \\
\text { layer 3 }\end{array}$ & $15 \sim 25$ & 1877.55 & 27.5 & 0.29 & 22 \\
\hline
\end{tabular}

Table 3 Material parameters

\begin{tabular}{cccc}
\hline Material & Density $\left(\mathrm{kg} / \mathrm{m}^{3}\right)$ & $\begin{array}{c}\text { Elasticity } \\
\text { modulus(MPa) }\end{array}$ & $\begin{array}{c}\text { Poisson } \\
\text { ration }\end{array}$ \\
\hline Rail & 2500 & 31500 & 0.3 \\
Tunnel Lining & 784 & 210000 & 0.2 \\
Floating Slab & 2500 & 35000 & 0.167
\end{tabular}

Backfill Layer 2500

28000 0.167

The hard contact model was applied in the normal direction of the wheel-rail contact surface and the coulomb friction contact model was applied in the tangential direction of the wheel-rail contact surface. The static friction coefficient was set as 0.3. According to Ref. [19], when the number of train bogies is set to 2 , the dynamic response results that are consistent with the actual results can be obtained. And this simplification can greatly improve the calculation speed. So in this paper, 2 bogies were used.

Table 4 The vehicle and the rail model parameters

\begin{tabular}{ccccc}
\hline $\begin{array}{c}\text { Length of } \\
\text { carriage }\end{array}$ & $\begin{array}{c}\text { Length of } \\
\text { wheelbase }\end{array}$ & $\begin{array}{c}\text { Distance between } \\
\text { front and rear bogies }\end{array}$ & $\begin{array}{c}\text { Standard } \\
\text { gauge }\end{array}$ & $\begin{array}{c}\text { Train } \\
\text { speed }\end{array}$ \\
\hline $19.0 \mathrm{~m}$ & $2.2 \mathrm{~m}$ & $12.6 \mathrm{~m}$ & $1435 \mathrm{~mm}$ & $\begin{array}{c}60 \\
\mathrm{~km} / \mathrm{h}\end{array}$ \\
\hline
\end{tabular}

\subsection{Determination of the train-induced vibration load}

Research shows that the main factors affecting the vibration load are the wheel-rail interaction and the dynamic effect. Currently, the fitting formula of the train-induced vibration load is generally used in numerical modeling [19]:

$$
F \quad t=P_{0}+P_{1} \sin \omega_{1} t+P_{2} \sin \omega_{2} t+P_{3} \sin \omega_{3} t
$$

where $P_{0}$ is the wheel static load; $P_{1}, P_{2}$, and $P_{3}$ are vibration loads. The corresponding vibration load amplitude is expressed as follows

$$
P_{i}=M_{0} \alpha \omega_{i}^{2} \quad i=1,2,3
$$

where $M_{0}$ is the mass of the train, $\alpha_{i}$ is the typical vector height, and $\omega_{i}$ is the circular frequency of the uneven vibration wavelength at the corresponding vehicle speed.

$$
\omega_{i}=\frac{2 \pi v}{L_{i}} \quad i=1,2,3
$$

where $v$ is the train speed; $L_{i}$ is the typical wavelength. The specific parameters are shown in the Table 5. Figure 10 shows the time-history curve of the train vibration load.

Table 5 The specific parameters of the fitting formula

\begin{tabular}{cccc}
\hline Parameters & Values & Parameters & Values \\
\hline$P_{0}$ & $80 \mathrm{kN}$ & $M_{0}$ & $750 \mathrm{~kg}$ \\
$L_{1}$ & $10.0 \mathrm{~m}$ & $\alpha_{1}$ & $3.5 \mathrm{~mm}$
\end{tabular}


$\begin{array}{llll}L_{2} & 2.0 \mathrm{~m} & \alpha_{2} & 0.4 \mathrm{~mm}\end{array}$

$\begin{array}{llll}L_{3} & 0.5 \mathrm{~m} & \alpha_{3} & 0.08 \mathrm{~mm}\end{array}$

In order to describe the form of the vibration load on the wheel and rail of the tunnel accurately, the vibration load of the train is applied to the center of mass of the wheel, at the same time, the running speed is applied to the train.

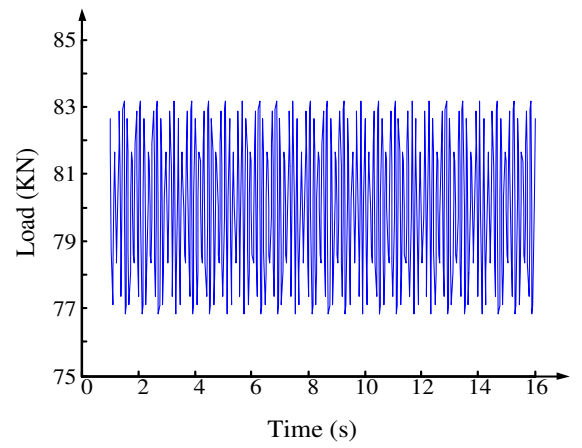

Figure 10 The fitting curve of the vibration load $(60 \mathrm{~km} / \mathrm{h})$

\section{Vibration response analysis of the billboard under different loads}

\subsection{Vibration response analysis of the billboard under} the train-induced vibration load

According to the measured data of the shield tunnel, it can be found that the vibration duration of the train from the approach to the departure of the monitoring point is about $14 \mathrm{~s}$ [20]. In order to conform to the actual running state, it is considered that the train is far away from the billboard in $0 \sim 16.7 \mathrm{~s}$, and train-induced vibration will not affect the billboard, so the vibration load will not be applied in this period. The train remains stationary and ignore the effect of wind load on the system, the vibration load is set form $16.7 \mathrm{~s}$ to $33 \mathrm{~s}$, and the train runs continuously at $60 \mathrm{~km} / \mathrm{h}$.

Figures 11 and 12 show the maximum von Mises equivalent stress contour of the billboard and the tunnel under the vibration load. As shown in Figure 11, the stress of the central position of the billboard is higher than the left and right edges, and the stress of top and bottom edges are higher than the middle. In Figure 12, when subjected to vibration load only, the maximum stress occurs on the rail, followed by the stress on the floating slab and the minimum stress is on the tunnel lining. The main reason is that the train-induced vibration load is generated just because of the impact between the wheel and the rail, so the stress at the rail is the largest. Compared with the floating slab and the rail, the stress of the tunnel lining is the smallest. The vibration load is transferred from the rail to the tunnel lining, and the corresponding attenuation becomes obvious as the transmission distance increases. Meanwhile, the stress in the area through which the train passes is greater than that in other areas.

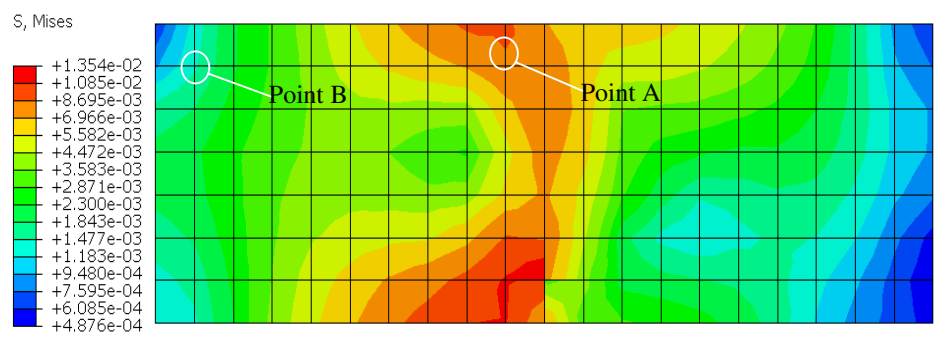

Figure 11 Von Mises equivalent stress contour of the billboard under the vibration load (MPa)

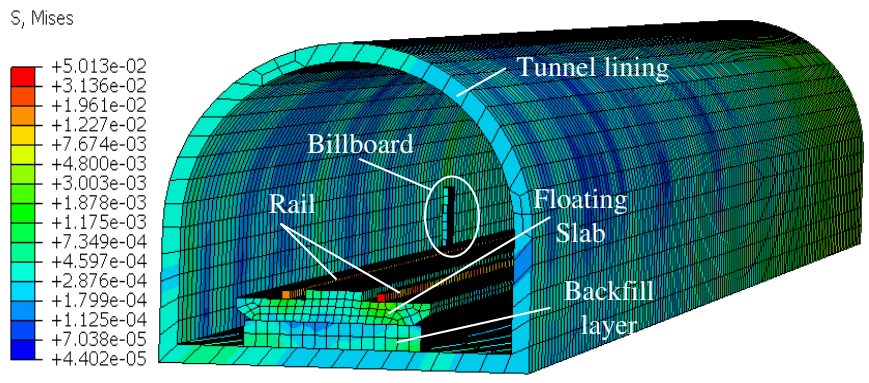

Figure 12 Von Mises equivalent stress contour of the tunnel under the vibration load (MPa)

The maximum stress on the billboard occurs at point $\mathrm{A}$ and the maximum acceleration on the billboard occurs at point B. The stress time-history curve of point A and the acceleration time-history curve of point $B$ are shown in 
Figures 13 and 14. The stress amplitude at point $\mathrm{A}$ is closely related to the running state of the train and increases as the train approaches. At $25.9 \mathrm{~s}$, the billboard vibrates the most violently of the whole time, and its maximum von Mises equivalent stress reaches $8.64 \mathrm{kPa}$. Then, the stress decrease with the train leaving and finally it approaches to $0 \mathrm{~Pa}$. The trend of acceleration time-history curve is same as the stress curve. As the train approaching, it gradually increases, and as the train moved away, it returns to 0 . The acceleration reaches its maximum of $2.1 \mathrm{~m} / \mathrm{s}^{2}$ when the train passes the billboard.

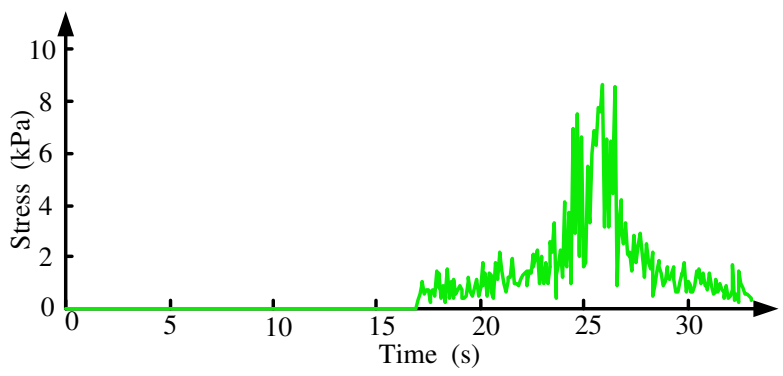

Figure 13 Time-history curve of von Mises equivalent stress at point $\mathrm{A}$ under the vibration load

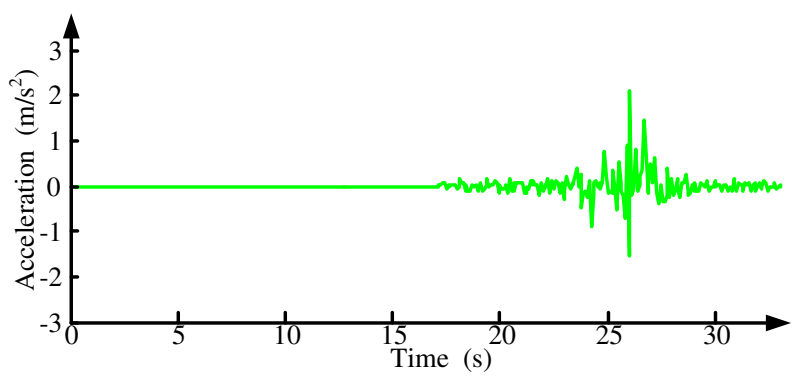

Figure 14 Time-history curve of acceleration at point B under the vibration load

\subsection{Vibration response analysis of the billboard under the wind load}

The wind load obtained by FLUENT is loaded on the surface of billboard by the form of pressure in ABAQUS to study the vibration response of the billboard under the wind load. The tunnel, train and model parameters are the same as those before. The wind load is set from 0 to $33 \mathrm{~s}$, the von Mises equivalent stress contour of the billboard and the tunnel under the wind load is shown in Figures 15 and 16.

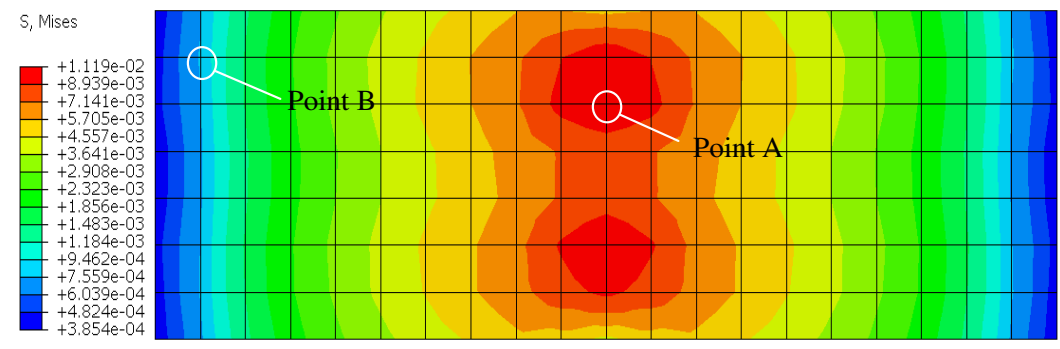

Figure 15 Von Mises equivalent stress contour of the billboard under the wind load (MPa)
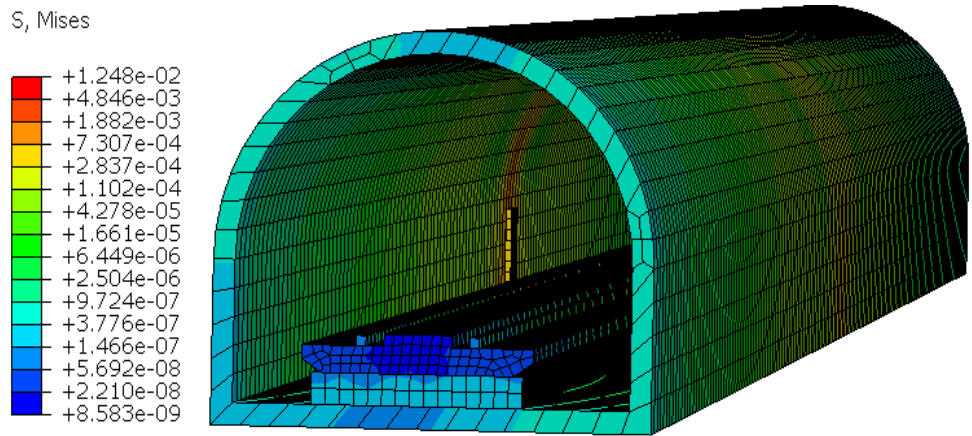

Figure 16 Von Mises equivalent stress contour of the tunnel under the wind load (MPa).

In Figure 15, the stress in the center of the billboard under the wind load is the highest, while the stress in the edge is relatively small, and this state is maintained throughout the operation of the train.
As is shown in Figure 16, only considering the effect of the wind load, the maximum stress is occurred at the billboard. Meanwhile, the farther away from the billboard, the smaller the stress cause by the wind load. And due to 
the vibration propagation and attenuation, the stress reaches its minimum at the rail.

The stress time-history curve of point $\mathrm{A}$ and the acceleration time-history curve of point $\mathrm{B}$ are shown in Figures 17 and 18. In Figure 17, it can be observed that the trend of the stress time-history is the same as the wind load curve. The von Mises equivalent stress of the billboard increase with the train operation, when the train reaches its fastest speed, the stress is also reached a maximum of 20.8 $\mathrm{kPa}$. Afterward, with the train speed keeping in a constant value, the piston wind in the tunnel gradually stabilizes, so that the stress on the point $\mathrm{A}$ is basically unchanged. Finally, with the departure and deceleration of the train, the wind load and the stress of the billboard decreases gradually.

In the initial stages, the acceleration of billboards fluctuates due to the sudden application of the wind load. The wind load is small and little change throughout the train operation, so the acceleration is extreme small, which is range from -0.1 to $0.4 \mathrm{~mm} / \mathrm{s}^{2}$.

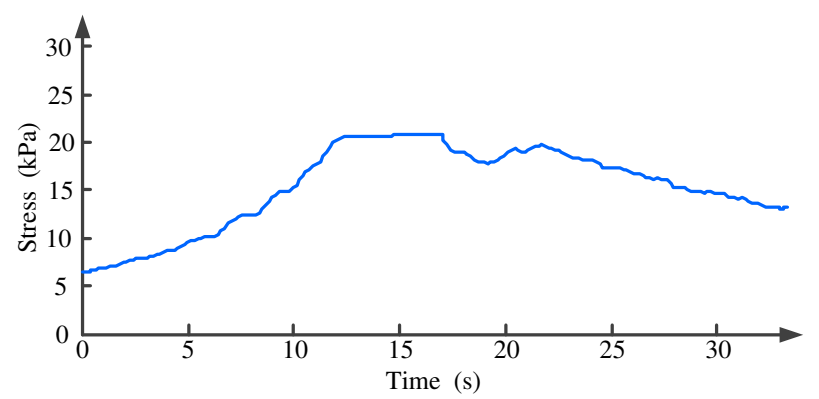

Figure 17 Time-history curve of von Mises equivalent stress at point $A$ under the wind load

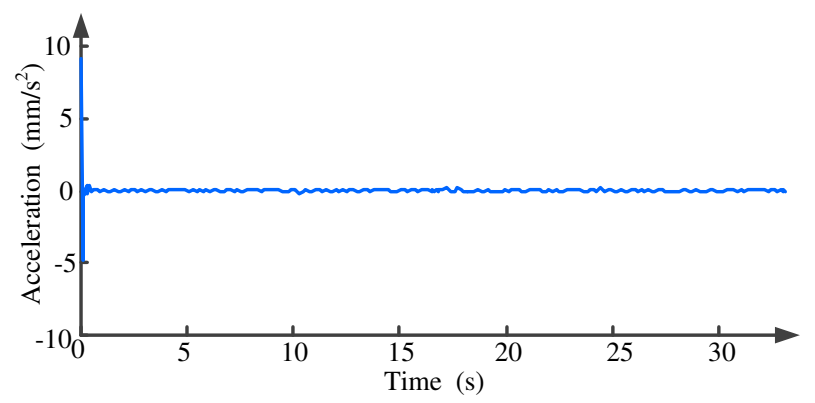

Figure 18 Time-history curve of acceleration at point B under the wind load

\subsection{Vibration response analysis of the billboard under multi-load}

In order to analyze the dynamic characteristics of billboards under the wind load and vibration load, simulate the train running in the subway tunnel and apply wind load to the surface of the billboard, the stress contours of the billboard and tunnel are shown in Figures 19 and 20.
As shown in Figure 19, the von Mises equivalent stress distribution of the billboard is symmetrical. The stress in both sides of the billboard is pretty small. The maximum stress occurred in the central position of the billboard.

In Figure 20, it is clearly showed that higher stress is always maintained in the rail, and the stress in the billboard takes the second place. Meanwhile, the closer to the vibration source, the vibration response is more severe. The stress in the middle of the tunnel is larger than the stress value at the entrance and exit. Moreover, the vibration of tunnel ground is much smaller than the rail, it indicate that the floating slab and backfill layer can effectively reduce the vibration of tunnel lining caused by train.

Point $\mathrm{A}$ and $\mathrm{B}$ are the maximum stress and acceleration points of the billboard. The time-history curve of point A and $\mathrm{B}$ under different loads are shown in Figures 21 and 22. In Figure 21, the train-induced vibration load is considered after $16.7 \mathrm{~s}$, so from 0 to $16.7 \mathrm{~s}$, the stress caused by the vibration load is taken as $0 \mathrm{~Pa}$. At that time, the time-history curves of wind load and multi-load are completely coincide. Since the train vibration load is applied, the time-history curves of wind load and multi-load start to separate. It is clearly showed that compared with only one type of load, the vibration of billboard under multi-load is more intense, and its response is larger than that of single load. Comparing the von Mises equivalent stress caused by different loads, it can be seen that although the vibration load affects the billboard in tunnel, its influence is less than that of wind load. It is because the wind load directly acts on the surface of the billboard, while the vibration load passes through the floating slab, the backfill layer and the tunnel lining to transmit to billboard. Each pass is accompanied by the transmission and attenuation of the stress wave, so that the vibration load is weakened.

As is shown in Figure 22, the wind load has little effect on the acceleration of the billboard in the tunnel, while the change trend of acceleration of billboard is basically the same when the billboard bears the vibration load and the multi-load. Under the vibration load, the acceleration range of the billboard is $-1.532 \sim 2.113 \mathrm{~m} / \mathrm{s}^{2}$, and under the multi-load, the acceleration range is $-1.634 \sim 2.216 \mathrm{~m} / \mathrm{s}^{2}$. Compared with the vibration load, the effect of wind load on the acceleration is very small, which can be ignored. 


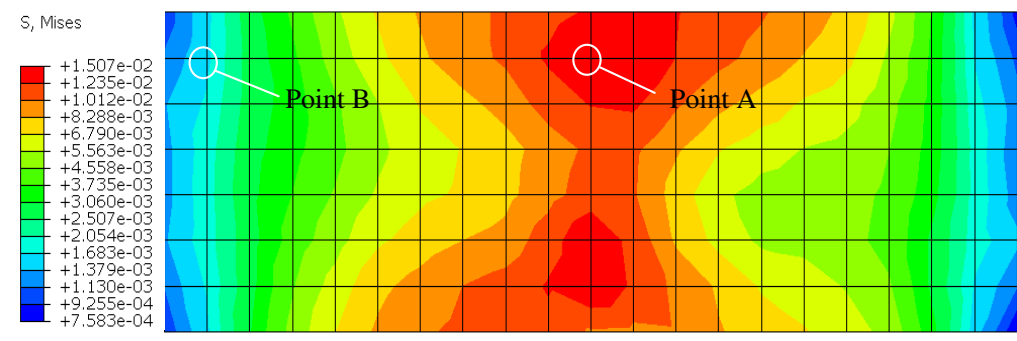

Figure 19 Von Mises equivalent stress contour of the billboard under the vibration load and the vibration load (MPa)

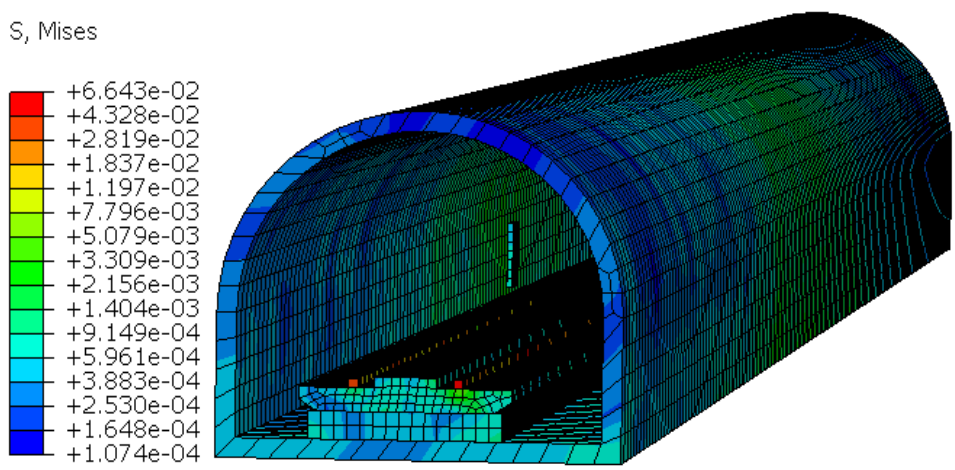

Figure 20 Von Mises equivalent stress contour of the tunnel under the vibration load and the vibration load (MPa)

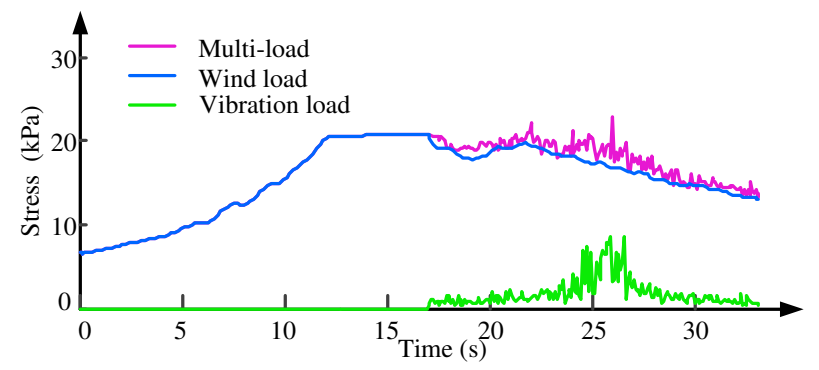

Figure 21 Time-history curve of von Mises equivalent stress at point A under different loads

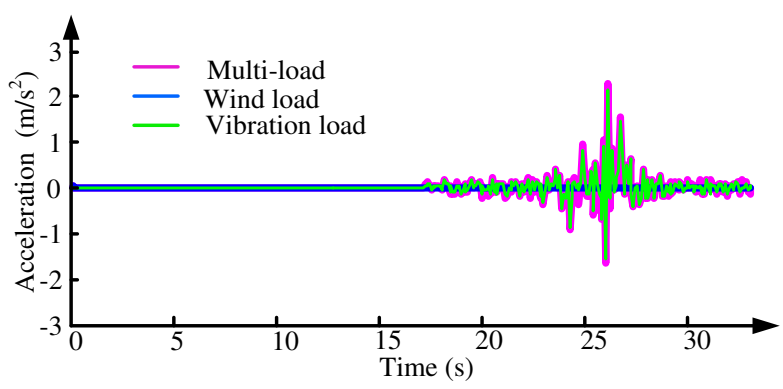

Figure 22 Time-history curve of acceleration at point B under different loads

\section{Conclusions}

For avoiding the damage of billboards in the subway tunnel, the structural response of them under the wind load, the vibration load and the multi-load were analyzed.
Specific conclusions drawn from this research are as follows:

(1) Only considering the dynamic response of the billboard under the wind load, the maximum von Mises equivalent stress of it is much greater than that of other loads, while the acceleration is smaller than that of other loads. When only the influence of vibration load is considered, the maximum von Mises equivalent stress of the billboard is smaller than that of other loads, but it has a great influence on the acceleration of the billboard. It denotes that only consider a single load to predict the billboard dynamic response is pretty conservative.

(2) The wind load and the vibration load have an important effect on reliability and safety of the billboard. When two different kinds of loads are loaded at the same time, the dynamic response is not simply calculated by adding the results of both two loads. The response under multi-load includes the characteristics of two loads acting separately. It is necessary to consider different loads when predicting the dynamic response of tunnel affiliated facilities.

(3) From an engineering point of view, we can take some measures to prolong the safety life and improve the reliability of billboards in the tunnel. Such as 1) add spring washer at the junction of the billboard and the wall to reduce the vibration; and 2) change the billboard structure to reduce the wind pressure, etc. 


\section{Declaration}

\section{Acknowledgements \\ Not applicable.}

\section{Funding}

Supported by National Natural Science Foundation of China (Grant No. 11872148), Fundamental Research Funds for the Central Universities of China (Grant No. N170308028, N180703018, N2003012, N2003013).

\section{Availability of data and materials}

The datasets supporting the conclusions of this article are included within the article.

\section{Authors' contributions}

The author' contributions are as follows: ZL was in charge of the whole trial; YS wrote the manuscript; YW, $\mathrm{KW}$ and GH assisted with simulation and analysis. All authors read and approved the final manuscript.

\section{Competing interests}

The authors declare no competing financial interests.

\section{Consent for publication}

Not applicable

\section{Ethics approval and consent to participate}

Not applicable

\section{References}

[1] S Liao, J Liu, R Wang, Z Li. Shield tunneling and environment protection in shanghai soft ground. Tunnelling and Underground Space Technology, 2009, 24(4): 454-465.

[2] M Wang. Discussion on design of fire door of underground connection passage. Journal of Railway Engineering Society, 2013, 30(4): 116-119. (in Chinese)

[3] J Y Kim, K Y Kim. Experimental and numerical analyses of train-induced unsteady tunnel flow in subway. Tunnelling and Underground Space Technology, 2007, 22(2): 166-172.

[4] G Han, Z Luo, Y Sun, et al. Time-variant characteristic under the piston wind on subway tunnel billboard. Proceedings of the iMeche, Part C: Journal of Mechanical Engineering Science, 2019, 233(16), 5637-5646.

[5] F E Camelli, G Byrne, R Löhner. Modeling subway air flow using CFD. Tunnelling and Underground Space Technology, 2014, 43(7): 20-31.

[6] L Yang, Y Zhang, Xia J. Case study of train-induced airflow inside underground subway stations with simplified field test methods. Sustainable Cities and Society, 2018, 37: 275-287.
[7] J Forrest, H Hunt. A three-dimensional tunnel model for calculation of train-induced ground vibration. Journal of Sound and Vibration, 2006, 294: 678-705.

[8] Z Yuan, Y Cai, L Shi, et al. Response of rail structure and circular tunnel in saturated soil subjected to harmonic moving load. Chinese Journal of Geotechnical Engineering, 2016, (2): 311-322. (in Chinese)

[9] W Gardien, H Stuit. Modelling of soil vibrations from railway tunnels. Journal of Sound and Vibration, 2003, 267(3):605-619.

[10] H Hung, L Hsu. Ground vibrations due to underground trains considering soil-tunnel interaction. Interaction and Multiscale Mechanics, 2007; 1:157-175.

[11] Q Yan, C Chen, X Huang. Analysis on vibration response characteristics of cross structure between shield tunnels and cross passage induced by the train. China Civil Engineering Journal, 2015, 48(S1): 228-235. (in Chinese)

[12] Q Yan, L Song, H Chen, et al. Dynamic response of segment lining of overlapped shield tunnels under train-induced vibration loads. Arabian Journal for Science and Engineering, 2018, 43: 5439-5455.

[13] F Xue. Dynamic responses of subway tunnel in clay stratum to moving loads. Arabian Journal for Science and Engineering, 2017, 42: 1327-1340.

[14] T Real, C Zamorano, F Ribes, et al. Train-induced vibration prediction in tunnels using $2 \mathrm{~d}$ and $3 \mathrm{~d}$ fem models in time domain. Tunnelling and Underground Space Technology, 2015; 49: 376-383.

[15] ANSYS Ins. ANSYS FLUENT user's guide. Canonsburg: 2017.

[16] Dassault Systèmes. ABAQUS CAE. Vélizy Villacoublay Cedex: 2017.

[17] J Anderson, E Dick, G Degrez, et al. Computational Fluid Dynamics: An Introduction. 3rd ed. Berlin: Springer, 2009

[18] Q Yan, C Hang, W Chen, et al. Dynamic Characteristic and Fatigue Accumulative Damage of a Cross Shield Tunnel Structure under Vibration Load. Shock and Vibration, 2018, 9525680.

[19] T Tian. Study on the dynamic response of high-speed railway tunnel with cavities under the train load. Dissertation for the Doctoral Degree. Beijing: China Academy of Railway Sciences, 2017. (in Chinese)

[20] Q Yan, B Li, G Ping, et al. Dynamic response of a double-lined shield tunnel to train impact loads. Tunnelling and Underground Space Technology, 2016, 53(Mar.):33-45.

\section{Biographical notes}

Yong-hang Sun, born in 1996, is currently a master candidate at School of Mechanical Engineering \& Automation, Northeastern University, China.

E-mail: sunyonghang1014@gmail.com

Zhong Luo, born in 1978, is currently a professor at Northeastern University, China. He received his $\mathrm{PhD}$ degree from Northeastern University, China, in 2007. His research interests include mechanical dynamics and control, model test theory and method.

Tel: +86-2483680540; E-mail: zhluo@mail.neu.edu.cn

Yu Wang, born in 1997, is currently a master candidate at School of Mechanical Engineering \& Automation, Northeastern University, China.

E-mail: 1784586734@qq.com 
Kai Wei, born in 1997, is currently a master candidate at School of Mechanical Engineering \& Automation, Northeastern University, China.

E-mail: 1095423999@qq.com

Gui-xin Han, born in 1995, is currently a master candidate at
School of Mechanical Engineering \& Automation, Northeastern University, China.

E-mail: $1027904372 @ q q . c o m$ 


\section{Figures}

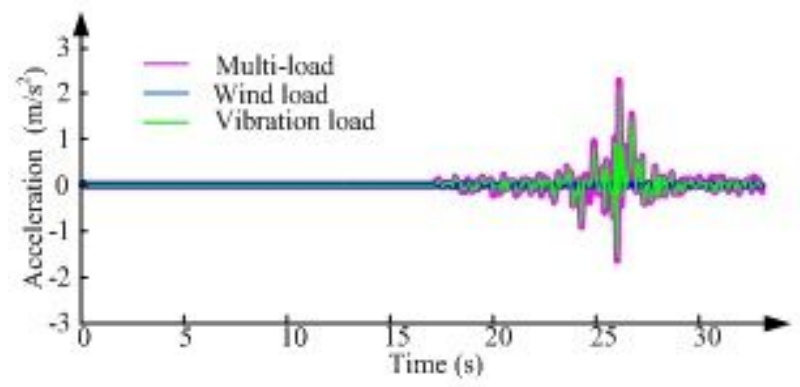

\section{Figure 1}

Time-history curve of acceleration at point B under different loads

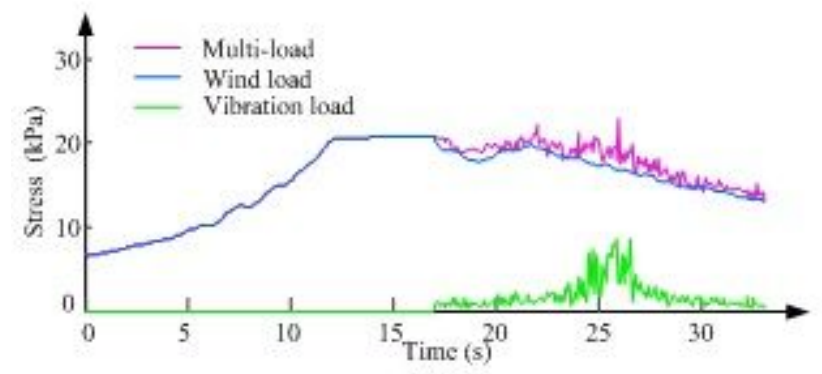

\section{Figure 2}

Time-history curve of von Mises equivalent stress at point A under different loads
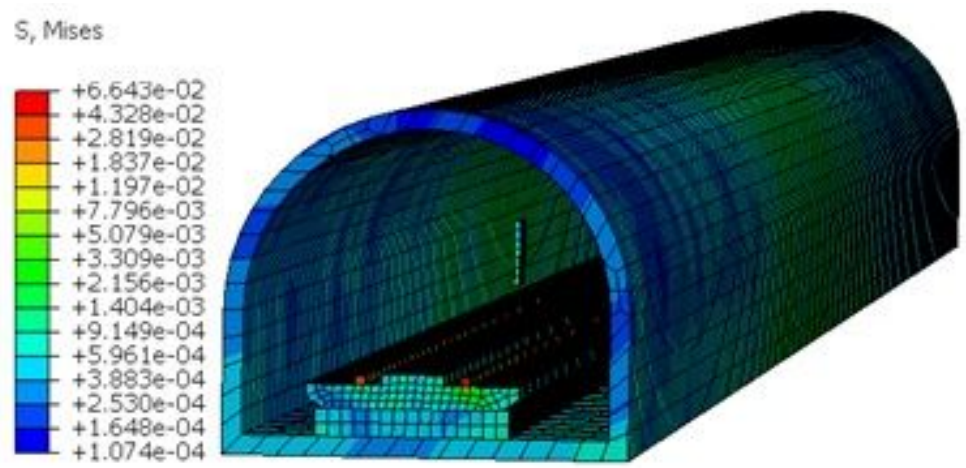

\section{Figure 3}

Von Mises equivalent stress contour of the tunnel under the vibration load and the vibration load (MPa)

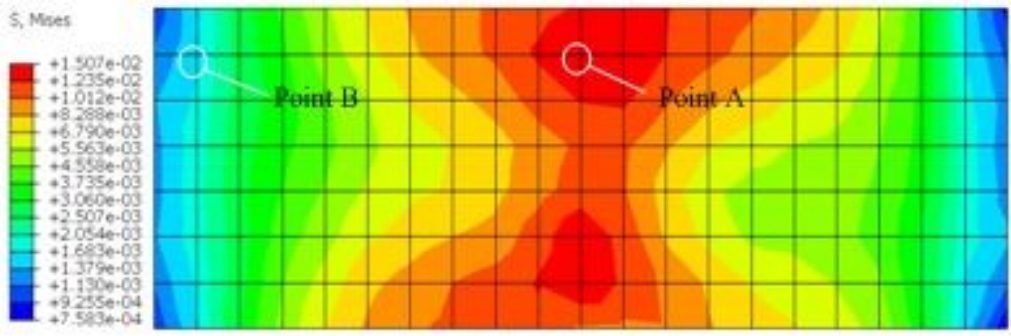


Figure 4

Von Mises equivalent stress contour of the billboard under the vibration load and the vibration load $(\mathrm{MPa})$

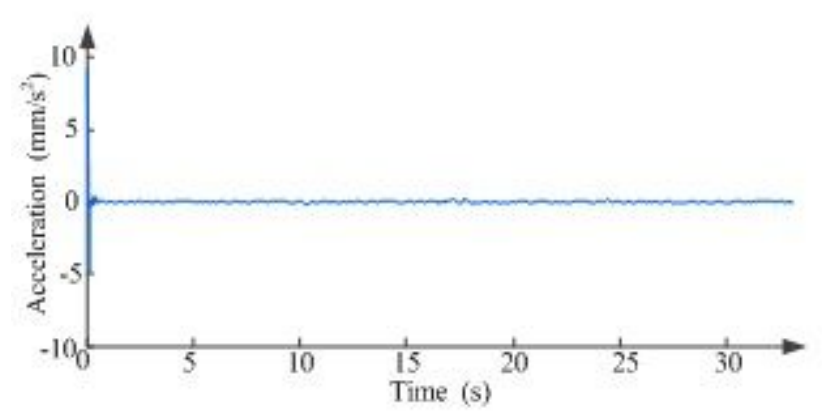

\section{Figure 5}

Time-history curve of acceleration at point B under the wind load

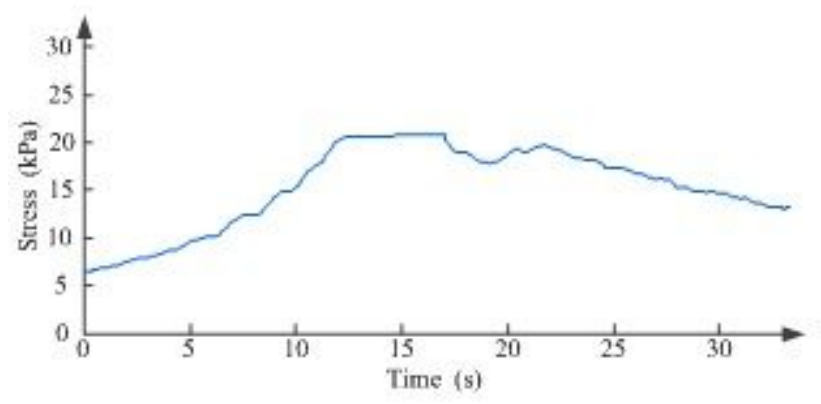

Figure 6

Time-history curve of von Mises equivalent stress at point A under the wind load s, Mses
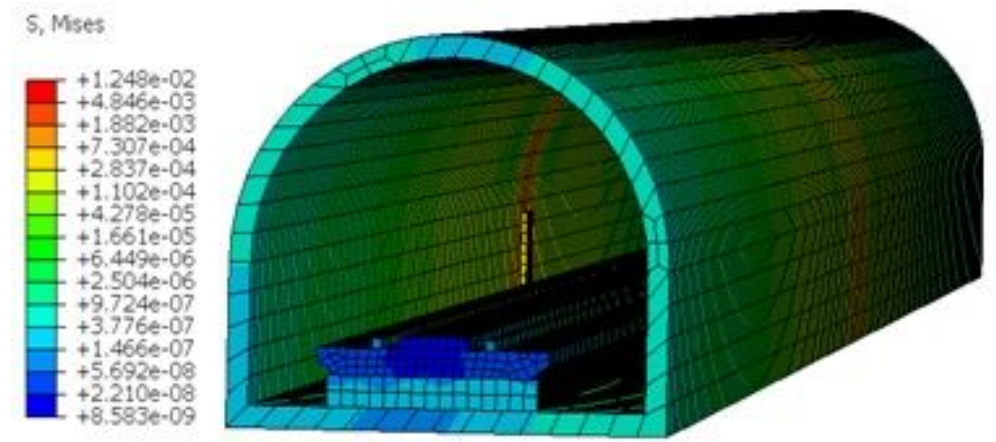

\section{Figure 7}

Von Mises equivalent stress contour of the tunnel under the wind load (MPa). 


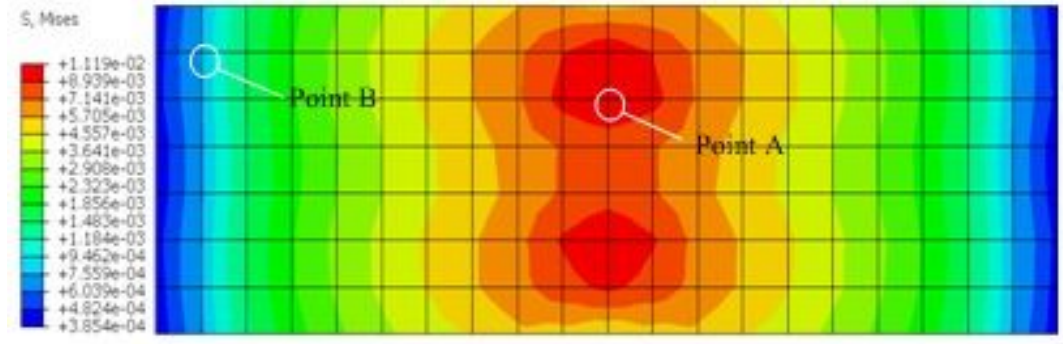

Figure 8

Von Mises equivalent stress contour of the billboard under the wind load (MPa)

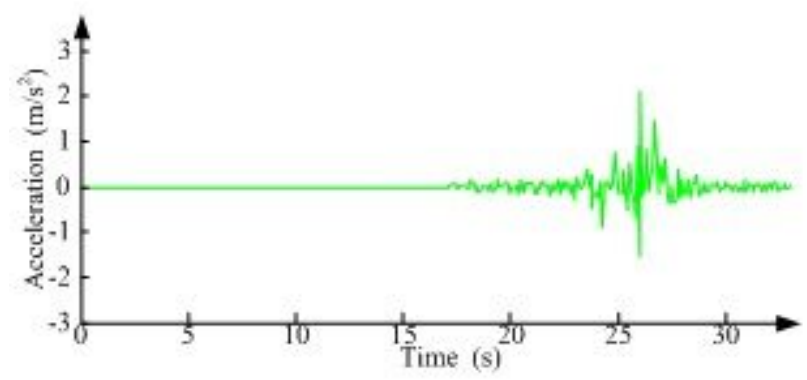

\section{Figure 9}

Time-history curve of acceleration at point B under the vibration load

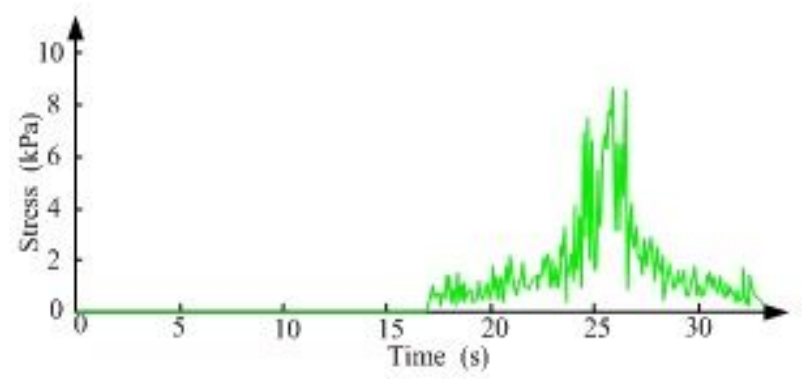

\section{Figure 10}

Time-history curve of von Mises equivalent stress at point A under the vibration load

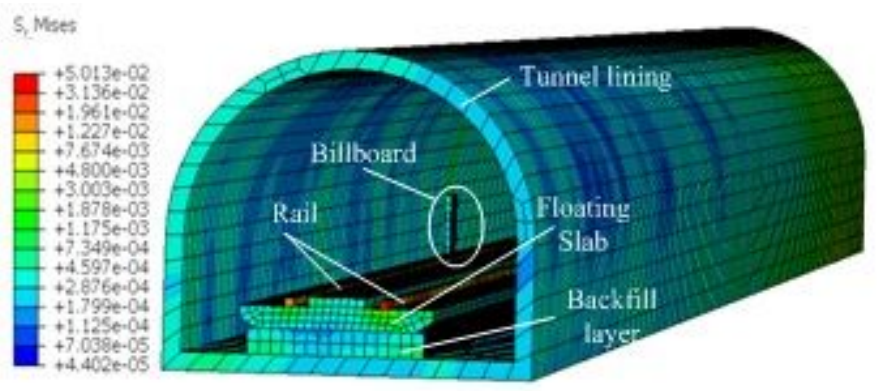

\section{Figure 11}

Von Mises equivalent stress contour of the tunnel under the vibration load (MPa) 


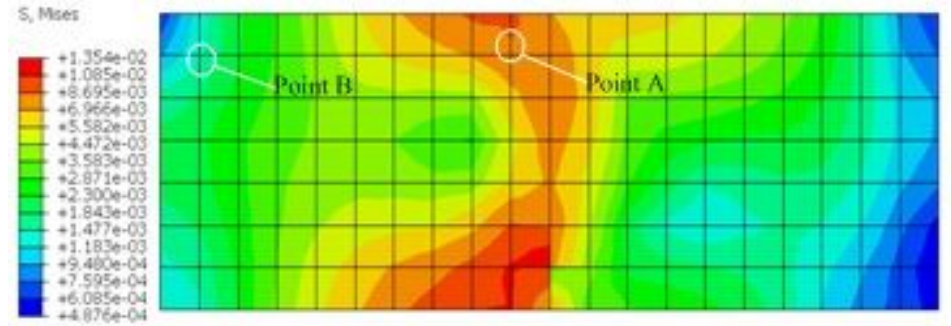

Figure 12

Von Mises equivalent stress contour of the billboard under the vibration load (MPa)

\section{Figure 13}

The fitting curve of the vibration load $(60 \mathrm{~km} / \mathrm{h})$

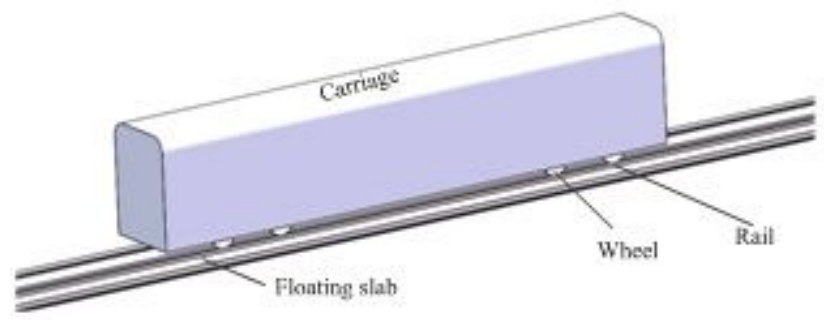

\section{Figure 14}

The vehicle and the rail model

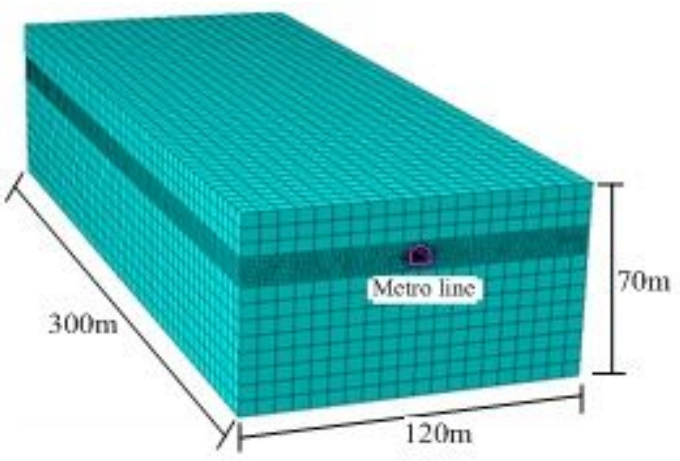

Figure 15

Finite element model of the tunnel

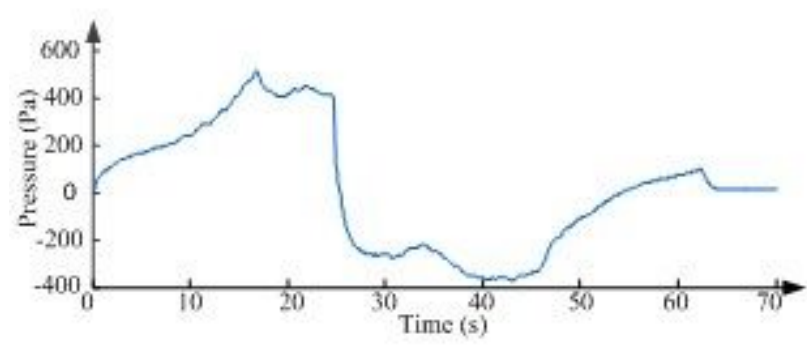


Figure 16

Pressure curve on the surface of the billboard at the train speed of $60 \mathrm{~km} / \mathrm{h}$

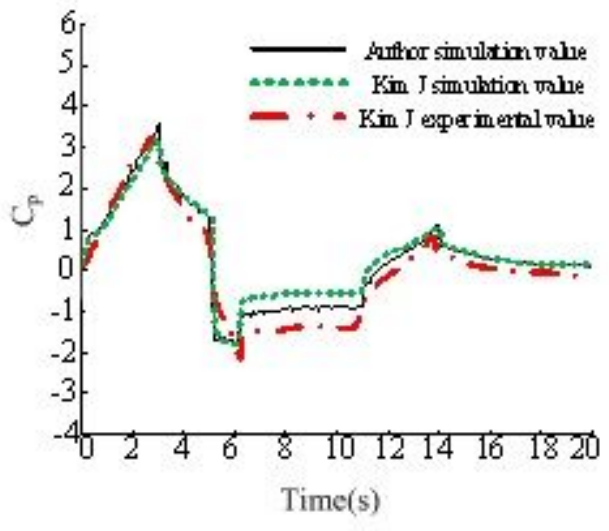

a

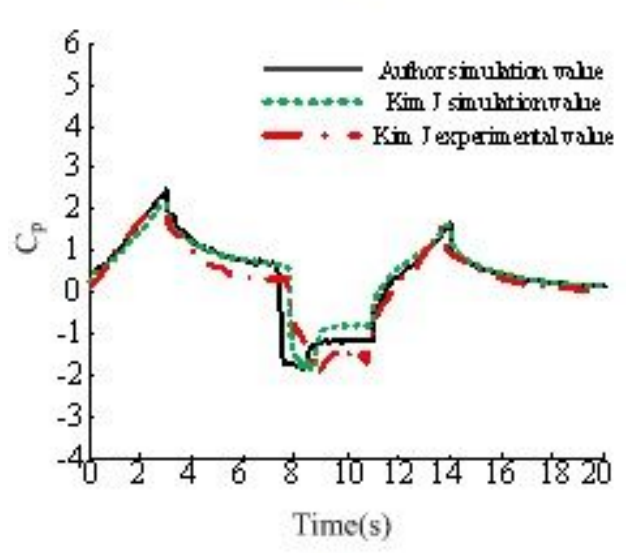

c

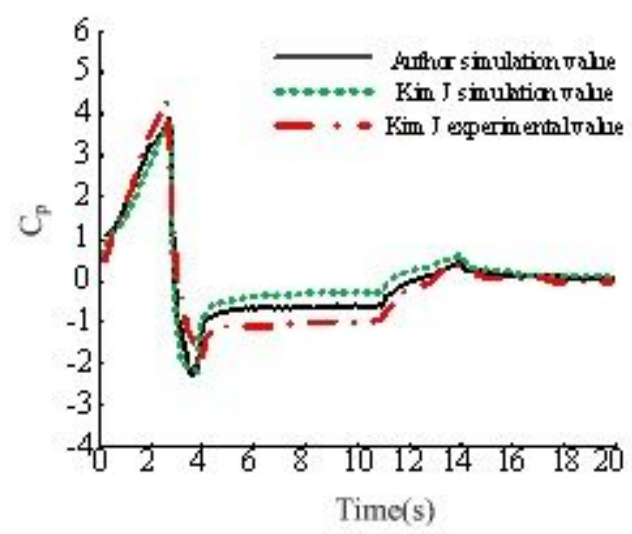

b

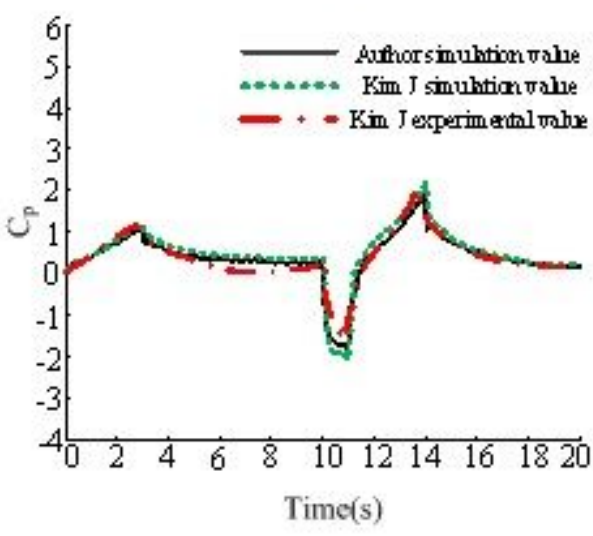

d

Figure 17

Comparisons of pressure coefficient Cp on monitoring points: (a) PT1; (b) PT2; (c) PT3; (d) PT4

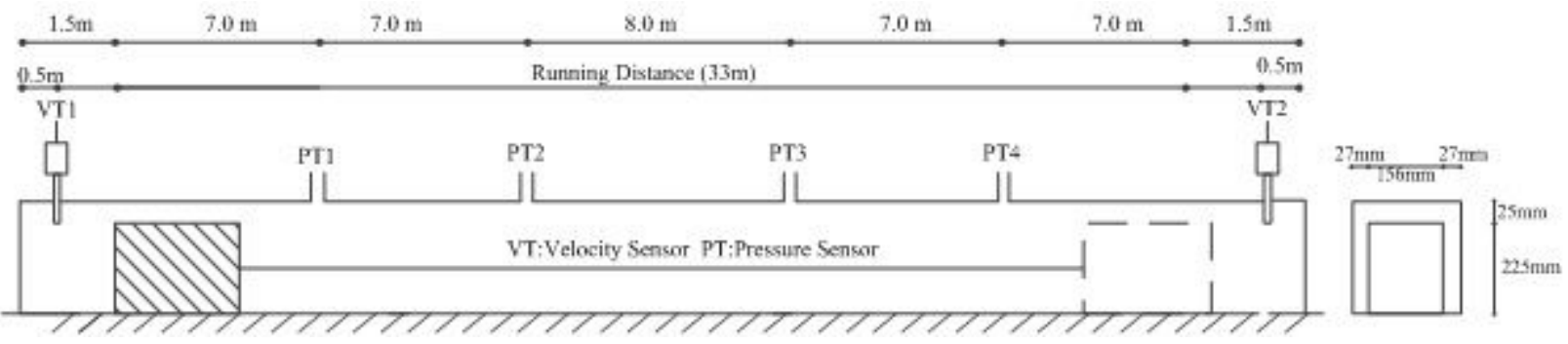

Figure 18

Schematic diagram of the experimental layout [3]. 


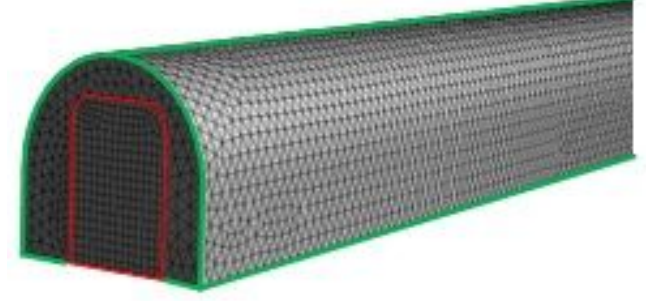

\section{Figure 19}

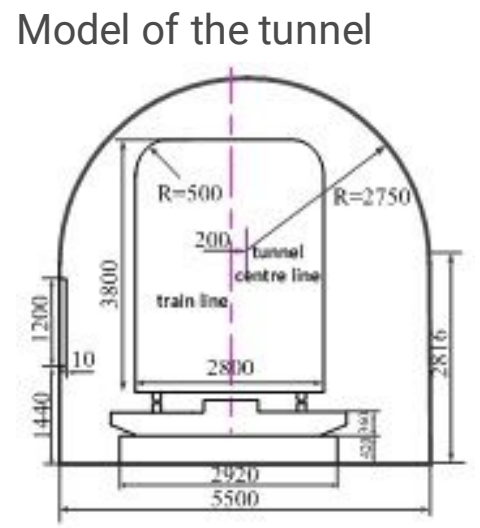

\section{Figure 20}

Cross section view of tunnel (mm)

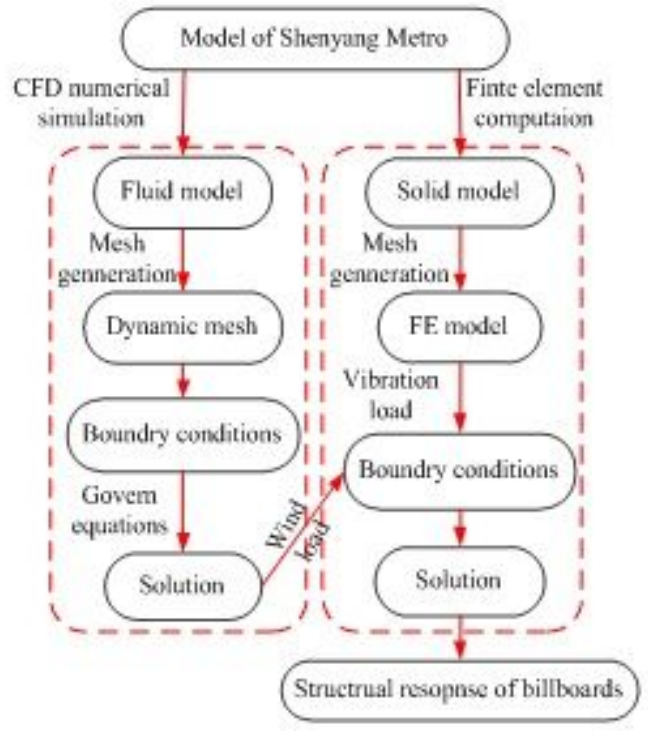

\section{Figure 21}

Flowchart of the study 


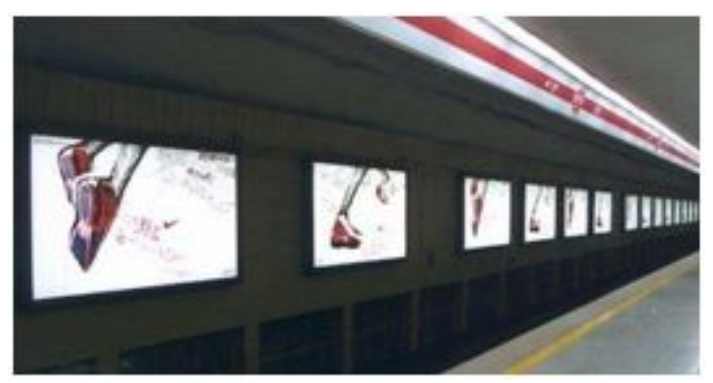

Figure 22

The billboards in tunnel 